on instruments at different epicentral distances, the differences being due to reflections and refractions of the various pulses in the interior of the earth. The suggestion by the late Prof. H. H. Turner of the occurrence of especially deep focus earthquakes had been confirmed by the work of Dr. R. Stoneley, Mr. F. J. Scrase and others, and this led Dr. H. Jeffreys to suggest that the hypothesis of Barrell was probably correct when he attributed finite strength to the earth down to a depth of about $700 \mathrm{~km}$. Further, the work of Dr. D. W. Phillips helps to explain the existence of aftershocks, in that it has been shown that rocks may possess several strengths according to the method of application and duration of the forces. The intensive study of deep focus earthquakes is likely to lead to solutions of some difficult seismological problems, including the depth of the core, the nature of the $20^{\circ}$ discontinuity, and the times of transmission of the transverse wave up to epicentral distances of about $25^{\circ}$.

In continuation, Dr. R. Stoneley showed that, as the result of considerable labour, Turner's readings of the $L$ phase of earthquakes corresponding to $0.48 \mathrm{~min}$./degree could be identified with long Rayleigh waves, and that the readings corresponding to $0.41 \mathrm{~min}$./degree could be assigned to the arrival of long waves first theoretically predicted by Prof. A. E. H. Love. The former are usually designated $L R$ waves and the latter $L Q$ waves. It is suggested that the difference between these two types of waves is due to differences at the origin. $L Q$ and $L R$ are well separated at distances greater than $50^{\circ}$.

Of interest to pure seismology is the work of Prof. J. D. Bernal, who concludes that there may be, at the pressures and temperatures existing at some depth within the earth, a denser and less compressible form of olivine, $(\mathrm{MgFe})_{2} \mathrm{SiO}_{4}$, than occurs normally on the surface. This would possibly explain the $20^{\circ}$ discontinuity. Crystallography should also be considered when discussing the structure of the earth's core.

Interesting on account of its application to both pure and applied seismology is the work of Dr. D. W. Phillips, who described experiments he has performed in compression, bending and torsion on coal measure sandstones, siltstones, mudstones, shales and coals, and also on some samples of marble. These experiments show up very clearly the imperfect elasticity of the rocks, which behave as perfectly elastic under stresses applied for a short time, but give 'hysteresis loops', possibly with complete recovery only after a very long time, when a stress is applied for a longer time. An interesting phenomenon found is that a stress large enough to give irrecoverable deformation may at first give only continuous deformation and yet lead to fracture if it is maintained long enough. Dr. Jeffreys showed later how this may account for the occurrence of continuous folding and fracture in the same arch, a common geological phenomenon. The fracture would cause an earthquake.

In the realm of applied seismology, Mr. T. F. Gaskell described the method of working and the results of the work of Dr. Bullard and himself. The method is to fire a small amount of gelignite and record automatically the seismic waves set up, by means of geophones at $200 \mathrm{ft}$. intervals up to $1,000 \mathrm{ft}$. , recording the initial time of the shock by a radio signal. From the resulting seismograms the shape of the palæozoic floor of part of eastern England has been determined, the process being facilitated by the fact that the wave velocities in the palæozoic rocks are high, whilst those in the chalk and overlying strata are low.

\title{
Educational Significance of the Cinema and Wireless
}

\begin{abstract}
A JOINT discussion at Cambridge on August 23 A between Section $J$ (Psychology) and Section L (Educational Science) on the cinema and wireless in education was opened by Mr. R. C. Steele, who dealt mainly with broadcasting.

Pointing out the remarkable growth in the use of broadcast methods since they were first introduced in schools fifteen years ago, especially in the last two years, Mr. Steele referred to the difficulty of evaluating their effects. He suggested that with dull or backward children the broadeast lesson is probably more effective in proportion to their ability than with the brighter pupils. It also offers a change from ordinary routine, presenting new material in a new and vivid way, which appeals to the imagination. $\mathrm{He}$ considers that with the backward child it is a further advantage that the broadcaster, though he may ask questions, does not expect answers, and the dull child may thus gain confidence instead of being made conscious of inferiority to others. Mr. Steele stressed the importance of personality and, discussing the use which could be made of broadcasting in education, suggested that where detail is of prime importance, as in a science lesson, the film is likely to be supreme. Where perfection of detail is less important and immediacy is the first consideration,
\end{abstract}

broadcasting and television may give the best results, and he predicted a great future for television in school teaching.

Mr. Steele's paper was supplemented by a paper by Miss L. M. Holt giving some statistical results of tests made with children who had been having wireless and ordinary lessons alternately, which were designed to determine the characteristic contributions of this new aid to teaching. The spontaneous contrasting of the facts in their possession was slightly higher in essays based on wireless lessons than in essays based on oral lessons, while a fine perception of specific or significant detail also characterized the wireless essays, indicating a good grasp of the subject.

Dr. P. B. Ballard, discussing the effect of wireless and the einema on the life of the school child, emphasized the experimental nature of the educational film as part of the school programme. It cannot be assumed that the child always prefers a talking to a silent film. There is direct evidence to the contrary, and for educational purposes the evidence indicates that the film should be short-for example, five to ten minutes - and unless the commentator speaks slowly and clearly and in simplified language appropriate to the audience, a silent film 
with printed captions is preferable. Reference was made to the bad influence of the ordinary cinema on children, particularly through displaying life not as service and quiet happiness but as self-indulgence and the mad pursuit of pleasure. Dr. Ballard was emphatic that ordinary broadcasting should not be allowed to curtail a child's necessary quota of sleep or to interfere with his homework.

Though broadcasting as compared with the educational film is comparatively mature, both methods have certain common characteristics and drawbacks. They are not complete educational units; there is no give and take between teacher and taught. They belong to the passive side of school work rather than the active-the impressional rather than the expressional. Both also have their affinity with mass instruction rather than with individual study. The capital virtue of the film is that it enriches the pupil's experience, while that of the radio talk is that it can do for the teacher what he could not do for himself. Dr. S. J. F. Philpott suggested that both methods may tend to diminish the gap between the dull and the brighter pupils.

The closeness with which a crowded audience followed the discussion bore witness to the deep interest in the possibilities of this new technique, and also to the realization of the dangers which attend its abuse in adult life as well as in childhood and adolescence.

\section{Professionalism in the Modern World}

$\mathrm{I}^{\mathrm{N}}$ a highly suggestive paper on "Professionalism" read before Section $\mathbf{F}$ (Economic Science and Statistics) at Cambridge on August 19, Mr. T. H. Marshall reviewed the development of the professions and discussed their place and inference in society to-day. According to Herbert Spencer, the history of the professions can be traced back to primitive societies. From the first they were nonmanual, and Mr. Marshall pointed out that their second characteristic was that they were not commercial, an ethical distinction clearly stated by the Greeks. Payment must not be the motive in professional work. The third characteristic of professionalism, the association, follows from the first two. It serves to maintain the power of brain-work to command the produce of manual labour, and it ensures that men, who must not work in order to be paid, are nevertheless paid enough to support them at the right social level. The official aim of a professional association is the preservation of a high standard of efficiency among its members. This is achieved by training and examining all candidates for admission and by obtaining privileges as against all non-members, which may amount to a legal monopoly. Such rights can only be claimed where the profession is based on a body of special knowledge or on a scientific technique which can be imparted in training colleges and tested by examinations. The typical professional association is a body that controls the application of science to the service of society.

In spite of this corporate responsibility to society, the professions are by tradition intensely individualistic, and the close personal relation of trust between the professional man and his client has proved an obstacle to the enlistment of the professions in the service of the State. Under the growth of science, the evolution of capitalism and the advance of democracy towards the social service State, not only have many new professions been developed but also the part played by personal character and tradition in the older professions has diminished. Capitalism requires professional men to work for impersonal corporations and may make him an employee. Democracy is leading the professional men to study the whole social background of the problems confronting him, and the professions are being transformed from strongholds of narrow individualism into most hopeful agencies for scientific social planning.

Simultaneously, Mr. Marshall pointed out, the antithesis between commerce and the professions has been greatly weakened. While the professions have been enlisted in the service of trade, the administration of trade is becoming professionalized. The salaried employees of big businesses are, like the professional man, neither capitalists nor wage-earners. Mr. Marshall suggested that they might become merged into a homogeneous social group, working not for profit, but for economic security, and out of interest in the job, a group favouring rational planning in public life, and individual freedom in private life, a group opposed to war whether between nations or between classes. There is much in common between professionalism in its modern form and some parts of the theory underlying Fascism. Moreover, if this new class is to be effective, either its tactics must be Fabian in the extreme or it must seek allies. Mr. Marshall suggested that the vital question is the attitude this new class is inclined to take up towards the conflict between capital and labour, or whether it is likely to evolve a system of its own differing from that advocated by either of the two contending parties. 